\title{
Patient and Physician Reported Perception on \\ Hypercholesterolemia Management in Primary Prevention in Germany: Results From a Nationwide Online Survey
}

\author{
L Beier \\ Novartis Pharma GmbH \\ M Wolf \\ genetischen Fettstoffwechselstörungen (CholCo) \\ K Stein \\ Novartis Pharma GmbH \\ Oliver Weingärtner ( $\nabla$ oliver.weingartner@med.uni-jena.de ) \\ Jena University Hospital
}

Cholesterin \& Co e.V.: Patientenorganisation für Patienten mit Familiärer Hypercholesterinämie oder anderen schweren

\section{Research Article}

Keywords: hypercholesterolemia, low-density lipoprotein, primary prevention, patient management

Posted Date: February 9th, 2022

DOI: https://doi.org/10.21203/rs.3.rs-988544/v1

License: (c) (i) This work is licensed under a Creative Commons Attribution 4.0 International License. Read Full License 


\section{Abstract}

Aims: Effective hypercholesterolemia management is essential in primary prevention of cardiovascular events. PROCYON assessed the perception on hypercholesterolemia management in clinical practice in Germany.

Methods: The online survey included a patient questionnaire on treatment status and disease knowledge and a physician questionnaire on guideline awareness and patient management together with a conjoint analysis on cardiovascular risk factors.

Results: Of 3,798 patients included, 1,632 (43.0\%) received lipid-lowering medication. Of these, 790 (48.4\%) reported improved low-density lipoprotein cholesterol (LDL-C) levels, 670 (41.1\%) reported no improvement, and 172 (10.5\%) had no information. Of the treated patients with $\left(\mathrm{N}^{\prime}=790\right)$ and without $\left(\mathrm{N}^{\prime}=670\right)$ improvement, $52.4 \% \mathrm{vs.} 47.9 \%$ were on their initial drug and dose, $8.9 \%$ vs. $9.0 \%$ received multiple drug therapy, $34.7 \%$ vs. $38.8 \%$ reported a dose change, and $16.0 \%$ vs. $19.4 \%$ had discontinued at least one drug (multiple answers).

In total, 109 physicians participated. LDL-C level was attributed the highest relative importance (32.0\%), followed by diabetes (24.5\%) and systolic blood pressure (15.8\%). Lipid-lowering therapy is initiated at an LDL-C level >150 mg/dL by 63 physicians $(57.8 \%)$. One third $(n=35 ; 32.1 \%)$ stated that $\geq 60 \%$ of their primary prevention patients do not receive lipidlowering medication.

Conclusion: PROCYON identified a need for consequent LDL-C target-based treatment implementation.

\section{Introduction}

Cardiovascular disease (CVD) is the leading cause of death in Europe ${ }^{[1]}$ and accounted for $35 \%$ of all deaths in Germany in

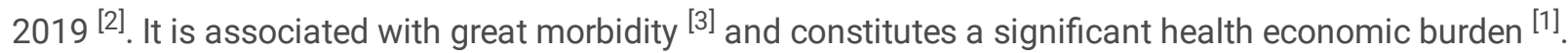

The 2019 guidelines of the European Society of Cardiology (ESC) and the European Atherosclerosis Society (EAS) for the management of dyslipidaemias recommend the validated SCORE system (Systemic Coronary Risk Estimation, www.heartscore.org) to assess the 10-year risk of fatal cardiovascular (CV) events. It is based on age, gender, smoking, systolic blood pressure, and total cholesterol ${ }^{[4]}$. Elevated low-density lipoprotein cholesterol (LDL-C) levels are a major risk factor for coronary heart disease (CHD) ${ }^{[5]}$ and major CV outcomes ${ }^{[6]}$. LDL-C lowering therefore is an essential part of the 2019 ESC/EAS guidelines for primary prevention of atherosclerotic CVD [4]. The target LDL-C level depends on the risk category: $<116 \mathrm{mg} / \mathrm{dL}$ for low-risk, $<100 \mathrm{mg} / \mathrm{dL}$ for moderate-risk, $<70 \mathrm{mg} / \mathrm{dL}$ and reduction of $\geq 50 \%$ for high-risk, and $<55$ $\mathrm{mg} / \mathrm{dL}$ and reduction of $\geq 50 \%$ for very-high-risk patients. Primary prevention patients with $\mathrm{CHD}$ or diabetes mellitus belong to the very-high-risk and high-risk category with a 10 -year risk of fatal CV events of $>10 \%$ and $>5 \%$ to $\leq 10 \%$, respectively.

An LDL-C reduction of $1 \mathrm{mmol} / \mathrm{L}(40 \mathrm{mg} / \mathrm{dL})$ reduced the risk for vascular mortality by $15 \%$ in a primary prevention population ${ }^{[7]}$. The 20-year follow-up of the WOSCOPS study showed the long-term benefits of statin treatment in primary prevention patients with LDL-C $\geq 160 \mathrm{mg} / \mathrm{dL}$. The risk for CHD death was significantly reduced by $28 \%$, the risk for CV death by $25 \%$ compared to patients who had initially received placebo. Further, the long-term WOSCOP analysis indicated a higher CV risk as a result of LDL-C-associated cumulative atherosclerotic burden ${ }^{[8]}$.

To achieve the LDL-C target levels, the guidelines recommend lifestyle and pharmacological intervention. The treatment scheme includes a first-line statin-based therapy and a combination of statins with ezetimibe, if the target of LDL-C is not attained with the maximally tolerated dose of statins. ${ }^{[4]}$. Further treatment options for patients insufficiently treated on background statins with or without ezetimibe include the addition of bile acid sequestrants, bempedoic acid or PCSK9 inhibition via PCSK9 antibodies or RNA interference ${ }^{[4]}$. LDL apheresis can be considered especially in patients with familial hypercholesterolemia $(\mathrm{FH}){ }^{[4]}$. A simulation suggested that even at high/very high risk, $99.3 \%$ of patients could reach an LDL- 
C level $<70 \mathrm{mg} / \mathrm{dL}$ with statins, ezetimibe, and proprotein convertase subtilisin/kexin type 9 (PCSK9) inhibitors ${ }^{[9]}$ and $90 \%$ a target level of $<55 \mathrm{mg} / \mathrm{dL}^{[10]}$.

However, real-world data from the DA VINCl study showed that among primary prevention patients only $63 \%$ with low risk, $60 \%$ with moderate risk, $25 \%$ with high risk and $11 \%$ with very high risk reached the 2019 EAS/ECS guidelines target levels

[11]. Overall, $50-75 \%$ of the patients were on low- or moderate intensity statin monotherapy ${ }^{[11]}$, indicating that therapeutic options were not fully exhausted.

The objective of the present survey was to assess the awareness for current LDL-C lowering strategies in primary prevention and to identify reasons for the discrepancy between the potential of available therapies and target attainment in clinical practice in Germany.

\section{Results}

\section{Participants and health care setting}

The survey was completed by 5,494 patients. 3,798 constitute the primary prevention population with a median age of 59.0 years and $70.7 \%$ female participants. The most common comorbidity was hypertension (Table 1). Hypercholesterolemia had mostly been diagnosed during routine check-up with a median time since diagnosis of 10.0 years (Table 1). Most patients consult their general practitioner for their hypercholesterolemia with an LDL-C assessment frequency of once a year or less in $53.2 \%$ of the patients (Table 1 ). 


\begin{tabular}{|c|c|}
\hline Patient survey & $\mathrm{N}=3,798$ \\
\hline & $\begin{array}{l}\text { n (\%), unless otherwise } \\
\text { specified }\end{array}$ \\
\hline Age in years, mean \pm SD [median] & $59.90 \pm 6.97[59.0]$ \\
\hline Female & $2,685(70.7)$ \\
\hline \multicolumn{2}{|l|}{ Comorbidities } \\
\hline Hypertension & $1,732(45.6)$ \\
\hline Obesity & $795(20.9)$ \\
\hline Diabetes type 1 & $61(1.6)$ \\
\hline Diabetes type 2 & $536(14.1)$ \\
\hline Other & $682(18.0)$ \\
\hline No & $1,336(35.2)$ \\
\hline Time since diagnosis in years, mean \pm SD [median] & $12.4 \pm 11.9[10.0]$ \\
\hline \multicolumn{2}{|l|}{ Reason for LDL-C assessment at diagnosis } \\
\hline Routine examination / check-up & $2,835(74.6)$ \\
\hline In combination with certain other diseases & $794(20.9)$ \\
\hline Family history & $312(8.2)$ \\
\hline Upon my request & $296(7.8)$ \\
\hline During hospital stay due to a heart attack, stroke, or other CVD & $251(6.6)$ \\
\hline Others & $106(2.8)$ \\
\hline I don't know & $52(1.4)$ \\
\hline \multicolumn{2}{|c|}{$\begin{array}{l}\text { Which doctor do you currently consult regarding your elevated cholesterol level? (Multiple } \\
\text { answers allowed) }\end{array}$} \\
\hline Family doctor / Internist & $3,335(87.8)$ \\
\hline Cardiologist & $617(16.3)$ \\
\hline Nephrologist & $103(2.7)$ \\
\hline Lipid clinic & $76(2.0)$ \\
\hline Others & $126(3.3)$ \\
\hline No doctor & $255(6.7)$ \\
\hline \multicolumn{2}{|l|}{ How often is your LDL cholesterol level measured? } \\
\hline Less than once a year & $809(21.3)$ \\
\hline Once per year & $1,213(31.9)$ \\
\hline Twice a year & $1,036(27.3)$ \\
\hline At least once every 3 months & 740 (19.5) \\
\hline
\end{tabular}


In total, 109 physicians participated in the survey. Characteristics and details on medical experience are presented in Table 2. Most physicians (86.2\%) stated that they are solely responsible for therapy decisions for hypercholesterolemia patients (Table 2). However, 85 physicians (58.6\%) reported a wish for more interdisciplinary cooperation in the management of hypercholesterolemia patients, and 42 (29.0\%) expressed a need for interdisciplinary networking and mutual exchange.

Table 2

Physician characteristics

$\begin{array}{ll}\text { Physician survey } & \mathrm{N}=109 \\ & \mathrm{n}(\%), \text { unless } \\ \text { otherwise } & \text { specified }\end{array}$

Specialization

General practitioners

$42(38.5)$

Internists

$44(40.4)$

Cardiologists

$23(21.1)$

Employment status

Employed

$7(6.4)$

Self-employed

$102(93.6)$

Years of clinical practice experience, mean \pm SD [median]

$17.64 \pm 8.65$

(18.0)

Years of clinical practice experience

1 to 10 years

$28(25.7)$

11 to 20 years

$40(36.7)$

21 to 30 years

$36(33.0)$

$>30$ years

$5(4.6)$

To what extent are you involved in the therapy decisions for hypercholesterolemia patients?

I am solely responsible for the therapy decision

I am jointly involved with other physicians in the therapy decision

$15(13.8)$

How many hypercholesterolemia patients do you treat who are receiving cholesterol-lowering therapy on prescription? Please indicate the average number in a normal period of 3 months.

Number of patients per quarter, mean \pm SD [median]

$299.04 \pm 201.03$

[250]

Do you refer patients to other physicians / medical specialists for diagnosis or for initiating a hypercholesterolemia therapy?

Yes

No

$84(77.1)$

\section{Physicians' disease awareness and guideline compliance}


Most physicians rated LDL-C as an important or very important risk factor and acknowledged its causal relationship with CV risk (Table 4). Agreement on the importance of cumulative LDL-C levels was lower (Table 4). Overall, 102 physicians (93.6\%) reported to perform routine checks for hypercholesterolemia and 104 (95.4\%) include LDL-C as a routine lipid test parameter.

Table 3

Relative importance of risk attributes from the physicians' conjoint analysis ( $\mathrm{N}=103)$

\begin{tabular}{|l|l|}
\hline Attribute & Relative Importance (\%) \\
\hline Age & 7.9 \\
\hline LDL-C level & 32.0 \\
\hline HDL-C level & 7.5 \\
\hline Smoking status & 12.2 \\
\hline History of diabetes & 24.5 \\
\hline Systolic blood pressure & 15.8 \\
\hline
\end{tabular}




\begin{tabular}{|c|c|}
\hline Physician survey & $N=109$ \\
\hline & $n(\%)$ \\
\hline \multicolumn{2}{|c|}{ How important do you consider the $L D L-C$ level for assessing the CV risk? } \\
\hline Very important & $\begin{array}{l}77 \\
(70.6)\end{array}$ \\
\hline Important & $\begin{array}{l}30 \\
(27.5)\end{array}$ \\
\hline Less important & $2(1.8)$ \\
\hline \multicolumn{2}{|c|}{ How would you describe the association between CV risk and LDL-C level? } \\
\hline Causal relation & $\begin{array}{l}105 \\
(96.3)\end{array}$ \\
\hline Poor evidence & $4(3.7)$ \\
\hline \multicolumn{2}{|c|}{$\begin{array}{l}\text { In your opinion, is a long-term elevated LDL-C level (cumulative exposure) a sufficiently accepted CV risk } \\
\text { factor? }\end{array}$} \\
\hline I fully agree & $\begin{array}{l}50 \\
(45.9)\end{array}$ \\
\hline I rather agree & $\begin{array}{l}47 \\
(43.1)\end{array}$ \\
\hline I rather disagree & $10(9.2)$ \\
\hline Do not agree at all & $2(1.8)$ \\
\hline \multicolumn{2}{|c|}{$\begin{array}{l}\text { In the absence of CV events, what LDL-C level do you consider to be in need of treatment? Please enter either } \\
\text { in } \mathrm{mg} / \mathrm{dL} \text { or } \mathrm{mmol} / \mathrm{L} \text {. }\end{array}$} \\
\hline$<70 \mathrm{mg} / \mathrm{dL}(<1.8 \mathrm{mmol} / \mathrm{L})$ & $2(1.8)$ \\
\hline $70-125 \mathrm{mg} / \mathrm{dL}(1.8-2.8 \mathrm{mmol} / \mathrm{L})$ & $\begin{array}{l}20 \\
(18.4)\end{array}$ \\
\hline $130-150 \mathrm{mg} / \mathrm{dL}(3.4-3.88 \mathrm{mmol} / \mathrm{L})$ & $\begin{array}{l}24 \\
(22.0)\end{array}$ \\
\hline $151-180 \mathrm{mg} / \mathrm{dL}(3.9-4.7 \mathrm{mmol} / \mathrm{L})$ & $\begin{array}{l}34 \\
(31.2)\end{array}$ \\
\hline $190-210 \mathrm{mg} / \mathrm{dL}(4.9-5.4 \mathrm{mmol} / \mathrm{L})$ & $\begin{array}{l}23 \\
(21.1)\end{array}$ \\
\hline$>210 \mathrm{mg} / \mathrm{dL}(>5.4 \mathrm{mmol} / \mathrm{L})$ & $6(5.5)$ \\
\hline
\end{tabular}

The conjoint analysis risk profiles were assessed by 103 physicians. The attribute with the highest relative importance was the LDL-C level, followed by diabetes, systolic blood pressure, and smoking status (Table 3).

Lipid-lowering therapy is initiated at an LDL-C level of $<125 \mathrm{mg} / \mathrm{dL}$ by $20.2 \%$, at $130-150 \mathrm{mg} / \mathrm{dL}$ by $22.0 \%$, and at $>150$ $\mathrm{mg} / \mathrm{dL}$ by $57.8 \%$ of physicians (Table 4 ). In total, 60 physicians $(55.0 \%)$ reported that $\geq 30 \%$ of their primary prevention patients are without drug therapy and $35(32.1 \%)$ have $\geq 50 \%$ of their primary prevention patients untreated. Results by medical specialization are presented in supplementary table $\$ 4$. 
The most common reasons for treatment escalation were target failure within 6 months $(n=67 ; 61 \%)$, a CV event ( $n=67$; $61.5 \%)$, or patient request $(n=30 ; 27.5 \%)$. Treatment is escalated if LDL-C target level is not reached after 8 weeks by $16.7 \%$ of the general practitioners, $9.1 \%$ of the internists and $47.8 \%$ of the cardiologists escalate treatment (Supplementary Table S4). In case of insufficient treatment or statin intolerance, the most common options are addition of ezetimibe or a switch to another statin (Figure 1 and Figure 2A). Insufficient target attainment is considered to be mostly due to a lack of lifestyle adaption and adherence, followed by side-effects and a lack of efficacy (Figure 2B). Among the different medical specializations, general practitioners consider a lack of lifestyle adaption as most important for not attaining target LDL-C level, while internists and cardiologists consider side-effects as well as lack of adherence most important (data not shown). In general, 86 physicians (78.9\%) are satisfied or very satisfied with the current treatment options.

\section{Patients' treatment status}

Less than half of the primary prevention patients stated that they receive lipid-lowering medication and half of the treated patients $(n=790,48.4 \%)$ stated that their LDL-C level has improved since diagnosis, 670 patients (41.1\%) reported no improvement (Table 5). Of the patients on drug therapy with $\left(N^{\prime}=790\right)$ and without $\left(N^{\prime}=670\right)$ LDL-C improvement, 52.4\% ( $n=414)$ vs. $47.9 \%(n=321)$ were on their initial drug at the same dose, $8.9 \%(n=70)$ vs. $9.0 \%(n=60)$ were on multiple drug therapy, $34.7 \%(n=274)$ vs. $38.8 \%(n=260)$ reported a dose change, and $16.0 \%(n=126)$ vs. $19.4 \%(n=130)$ had discontinued at least one drug (multiple answers allowed). Frequency of LDL-C assessments in treated patients without improvement $(\mathrm{N} \nabla=670)$ is once a year or less in 259 patients $(38.7 \%)$ and twice per year or more often in 411 patients $(61.3 \%)$.

Table 5

Treatment status and LDL-C target attainment (Patient survey)

\begin{tabular}{|c|c|c|}
\hline Patient survey & $N=3,798$ & \\
\hline Are you currently taking any medication to lower your LDL-C level? & $\mathrm{n}(\%)$ & \\
\hline No & $2,166(57.0)$ & \\
\hline Yes & $1,632(43.0)$ & \\
\hline \multirow[t]{2}{*}{$\begin{array}{l}\text { How has your LDL-C level changed since diagnosis? (according to your treating } \\
\text { physician) }\end{array}$} & $\begin{array}{l}\text { Treated } \\
\text { patients }\end{array}$ & $\begin{array}{l}\text { Untreated } \\
\text { patients }\end{array}$ \\
\hline & $(\mathrm{N} \mathbb{X}=1,632)$ & $(\mathrm{N} \mathbb{N}=2,166)$ \\
\hline Improved (lower) & $790(48.4)$ & $354(16.3)$ \\
\hline Same level & $240(14.7)$ & $736(34.0)$ \\
\hline Fluctuating (sometimes lower, sometimes higher) & $324(19.9)$ & $504(23.3)$ \\
\hline Worsened (higher) & $106(6.5)$ & $231(10.7)$ \\
\hline My doctor did not inform me about LDL-C changes & $172(10.5)$ & $341(15.7)$ \\
\hline
\end{tabular}

\section{Compliance, patient information and activation}

Physician perspective

All physicians consider patient information as important or very important for adherence. Overall, 100 physicians (91.7\%) stated that they inform patients about LDL-C targets and $77(70.6 \%)$ identified a need for more patient information material. Regarding their patients' level of knowledge, 81 physicians (81.0\%) answered that their patients know about LDL-C importance, 50 physicians (45.9\%) stated that their patients do not take the risk of hypercholesterolemia serious, and 70 physicians (55.0\%) assumed a lack of knowledge on the disease. 
The treating physician was mentioned as the most common source of information by 2,453 patients (64.6\%). The information received by their physician was rated as good or very good by 1,351 patients (35.6\%) and as sufficient by 1,496 (39.4\%). Patient groups are used for information by 63 patients (1.7\%). 946 patients $(24.9 \%)$ say they have good or very good knowledge about LDL-C. The importance of LDL-C reduction for lowering their CV risk is acknowledged by 3,234 patients (85.2\%). One third of the patients ( $n=1,242 ; 32.7 \%)$ know their current LDL-C level, and 1,006 patients (26.5\%) know their target LDL-C, of whom 754 (75.0\%) consider important to achieve the target.

Two third of the patients receiving lipid-lowering therapy consider their LDL-C medication as important as other medications (Table 6). The majority of patients rated themselves as treatment compliant and reported to take their medication as regularly or nearly as regularly as prescribed (Table 6). The most common reason for treatment discontinuation was side-effects (Table 6$)$. Less than one third of the patients $(n=1,073 ; 28.3 \%)$ are satisfied with their current treatment. The majority was either worried about their elevated LDL-C levels $(n=1,446 ; 38.1 \%)$, wished to receive another therapy $(n=492 ; 13.0 \%)$ or is bothered by the need for frequent drug administration $(n=431 ; 11.4 \%)$. 


\begin{tabular}{|c|c|}
\hline Patient survey (treated patients) & $N \otimes=1,632$ \\
\hline & $\mathrm{n}(\%)$ \\
\hline \multicolumn{2}{|l|}{ How regularly do you take your cholesterol-lowering medication (i.e. exactly as prescribed by your doctor) } \\
\hline Always & $1,165(71.4)$ \\
\hline Somewhat regularly & $328(20.1)$ \\
\hline Somewhat unregularly & $71(4.4)$ \\
\hline Very unregularly & $68(4.2)$ \\
\hline \multicolumn{2}{|l|}{ How important are your medications for treating $L D L-C$ to you compared to other medications you take? } \\
\hline Comparably important & $1,082(66.3)$ \\
\hline More important & $195(12.0)$ \\
\hline Less important & $182(11.2)$ \\
\hline Not important at all & $29(1.8)$ \\
\hline I do not take any other medications & $144(8.8)$ \\
\hline \multicolumn{2}{|l|}{ Have you experienced any side-effects due to your lipid-lowering medication? } \\
\hline No & $1,079(66.2)$ \\
\hline Yes & $552(33.8)$ \\
\hline If yes, what side effects did you experience? & $(\mathrm{N} \rrbracket=552)$ \\
\hline Muscular pains / muscle complaints & $430(77.9)$ \\
\hline Gastrointestinal complaints & $160(29.0)$ \\
\hline Vertigo & $148(26.8)$ \\
\hline Headache & $106(19.2)$ \\
\hline Others & $113(20.5)$ \\
\hline I have stopped at least one drug for cholesterol reduction & $277(17)$ \\
\hline Did you stop your discontinued medications to lower LDL-C on your own or on your doctor's advice? & $(\mathrm{N} \otimes=277)$ \\
\hline On doctor's advice & $145(52.4)$ \\
\hline On my own & $124(44.8)$ \\
\hline I have never taken medication to lower cholesterol levels & $8(2.9)$ \\
\hline Why did you stop taking these medications? & $(\mathrm{N} \rrbracket=269)$ \\
\hline Side effects & $212(78.8)$ \\
\hline Lack of improvement & $51(19.0)$ \\
\hline Lack of trust in the doctor / medication & $21(7.8)$ \\
\hline Others & $35(13.0)$ \\
\hline Uncertain & $11(4.1)$ \\
\hline
\end{tabular}


The most frequently reported adaptions since diagnosis were dietary changes (2,051 patients; $54.0 \%)$, followed by an increase in physical activity (1,500 patients; $39.5 \%)$, and lipid-lowering drug intake (1,300 patients; $34.2 \%)$. In total, 3,402 patients answered the patient activation measure (PAM) questionnaire. The results regarding the achieved PAM levels were as follows: PAM level 4: 442 patients (13.0\%); PAM level 3: 2,114 patients (62.1\%); PAM level of 2: 754 patients (22.2\%) and PAM level 1: 92 patients (2.7\%).

\section{Discussion}

The PROCYON survey revealed a high proportion of untreated patients and a lack of patient perceived improvement in LDL-C levels in $41 \%$ of patients on drug therapy. This is in line with US registry data, in which $63.9 \%$ of the primary prevention patients were untreated or treated on a lower intensity than recommended ${ }^{[12]}$.

In the conjoint analysis, physicians' assessment of risk factor relevance was in accordance with the ESC/EAS guidelines with elevated LDL-C levels as one of the main factors ${ }^{[4]}$. However, the survey indicates inadequate guideline implementation into clinical practice. Most physicians reported initiating pharmacotherapy for primary prevention only at LDL-C levels $>150$ $\mathrm{mg} / \mathrm{dL}$. This complies with the 2017 DEGAM (Deutsche Gesellschaft für Allgemeinmedizin und Familienmedizin) guideline on counseling on CV prevention in family medicine, which recommends to consider statin therapy at LDL-C levels $<195$ $\mathrm{md} / \mathrm{dL}$ only in case of high or very high CV risk ${ }^{[13]}$. In contrast, the ESC/EAS 2019 guidelines intend a target of $<116 \mathrm{mg} / \mathrm{dL}$ even for low-risk patients. Barter et al. reported a target level of $129 \mathrm{mg} / \mathrm{dL}$ in clinical practice in Germany and suggested that uncertainties related to statin safety and the safety of very low LDL-C levels might add to the reluctance to adopt the low target recommendations ${ }^{[14]}$. Furthermore, PROCYON indicated that the frequency of LDL-C assessments might be too low. More than one third of the patients with above-recommended LDL-C levels despite drug therapy undergo LDL-C assessments only once per year or less. An assessment once per year is standard in patients on LDL-C lowering therapy ${ }^{[4]}$, but a higher frequency should be considered until the target level is reached.

In addition, only half of the physicians were fully aware of cumulative LDL-C as a risk correlate of CVD. While pack years are established to quantify the cumulative impact of smoking, cumulative LDL-C exposure and the associated necessity of early screening and treatment is not fully acknowledged in primary care. Screening for hypercholesterolemia has just recently become reimbursable in Germany once between 18 and 34 years of age. From the age of 35 years onwards routine checks can be performed every 3 years ${ }^{[15]}$. However, earlier screening is supported by data on the high prevalence of elevated LDL-C levels in preschool children ${ }^{[16]}$.

PROCYON showed that treatment was often not escalated despite inadequate LDL-C reduction. Cardiologists tended to escalate earlier than general practitioners and internists. The reluctance might be attributable to the fact that the 2017 DEGAM guideline recommends a fixed-dose statin treatment instead of a treat-to-target approach and opts against a combination therapy ${ }^{[13]}$.

General practitioners thought that mainly a lack of lifestyle adaption impaired target attainment. However, even dramatic changes can only reduce LDL-C levels by 10 to $15 \%{ }^{[17]}$. Pharmacological intervention is essential for target attainment.

In contrast to general practitioners, internists and cardiologists considered adherence and tolerability as the most important reasons for missing the target. The high adherence rates reported by patients might reflect a participation bias, with high selfactivation in respondents. However, frequent patient-initiated treatment discontinuations rather suggest that patients overestimated their adherence, which is common due to social desirability and memory biases ${ }^{[18]}$. Improving adherence could constitute a major factor for treatment success with a potential in CHD risk reduction of $52 \%$ [19].

Previous studies revealed that negative media information about statins was a major driver of treatment discontinuation [20,

21]. A trusting patient-physician relationship that addresses the patients' risk perception, existing side-effects as well as 
information gaps, allows for correction of misinformation ${ }^{[22]}$. While the importance of patient information was generally accepted in PROCYON, the lack of knowledge on LDL-C targets and current levels indicate a need for well-composed educational material to support patient-physician communication. The involvement of patient organizations could further add to education and activation. Patients with $\mathrm{FH}$ and other severe hereditary lipid disorders in Germany can be referred to the "Cholesterin und Co e.V." (CholCo.org). For primary prevention patients without hereditary disorders, a patient organization has not been established yet.

The physician survey revealed a wish for interdisciplinary networking. Patient management could benefit from professional networks through facilitated transitory processes (i.e. between medical specialists, general practitioners, and lipid ambulances) and diagnosis of rare lipid disorders through lipid competence centers. Furthermore, networks could promote inter- and intradisciplinary exchange and continued training (e.g. qualification as certified "lipidologist") [23].

The present survey has some limitations. First, except for PAM-13, no validated questionnaire was available to support the study objective. Second, LDL-C levels collected in the patient survey were implausible and could not be interpreted, possibly due to confusion of the units. Patients could choose to enter their LDL-C levels in $\mathrm{mg} / \mathrm{dL}$ or $\mathrm{mmol} / \mathrm{L}$, as both units are used in Germany, depending on regional preference. The documented range in $\mathrm{mg} / \mathrm{dL}$ was $1.3-1,485$; the documented range in $\mathrm{mmol} / \mathrm{L}$ was 0 - 180,119. Therefore, assessment of LDL-C changes was based on the patients' perceived LDL-C development only. Third, web-based medical surveys are prone to a participation bias with higher level of education and better health state among the respondents compared to non-respondents ${ }^{[24]}$. Survey results might further be biased by social desirability [25] and participants with higher self-activation might be overrepresented as only responders who answered all questions were included. Survey participation of patients was not encouraged by incentives. Physicians received small expense allowance for participation, however, only a minor response bias is expected.

In summary, PROCYON has shown that adequate and effective interventions for optimization of hypercholesterolemia patient care are urgently needed. PROCYON identified potentials for improvement with respect to guideline awareness and implementation from a physician's perspective as well as improved risk awareness, disease knowledge, and adherence from a patient's perspective.

\section{Methods}

\section{Data collection}

PROCYON consisted of a patient and a physician survey which were active from September to November 2020.

Patients were required to meet the following criteria: (1) $\geq 18$ years of age; (2) currently living in Germany; and (3) diagnosis of hypercholesterolemia. Patients were identified by a service provider through newsletters and social media. Eligibility was screened via a questionnaire and eligible patients were invited to participate. The web-based questionnaire of the patient survey (see supplementary table S1) included up to 35 questions on hypercholesterolemia-related medical history, comorbidities, medication adherence, side-effects, disease knowledge, information generation, disease awareness and selfactivation. Patient self-activation was assessed by the Patient Activation Measure by Insignia Health (PAM-13), a 13-item measure developed to evaluate knowledge, skills and confidence essential to self-management of healthcare ${ }^{[26]}$. It defines four stages of activation with 1 being the lowest and 4 being the highest level of activation [27].

The following eligibility criteria were applied for the physician survey: (1) resident general practitioner, cardiologist or internist; (2) treats at least 50 patients with hypercholesterolemia per quarter; and (3) is in charge for treatment decisions. It was planned to include about 100 physicians in a 1:1:1 ratio (resident general practitioners, cardiologists and internists). In total, 14,060 eligible physicians in Germany were contacted by a service provider and invited to participate. The first 100 physicians who signed the participation agreement were to be included. No individual patient data were collected in the physician survey. The online questionnaire included up to 33 questions (see supplementary table S2) on LDL-C relevance, guideline awareness,

Page $12 / 16$ 
patient management, and treatment decisions. A conjoint analysis was used to assess the relative importance of risk factors for CVD. Among 10 sets with 3 patient profiles each (see example in supplementary table S3), physicians were requested to determine the profile with the highest $\mathrm{CV}$ risk. Patient profiles within one set had identical risk scores but varying risk factors (age, gender, HDL-C, LDL-C, diabetes, smoker, systolic blood pressure) based on the PROCAM score (Prospective Cardiovascular Munster study). The PROCAM score estimates the risk for myocardial infarction using age, LDL-C level, HDL-C level, smoking status, systolic blood pressure, family history of premature myocardial infarction, diabetes mellitus, and triglyceride levels ${ }^{[28]}$.

\section{Statistics}

Patients and physicians who answered all questions were included in the analysis. The present patient survey analysis included primary prevention patients without myocardial infarction, stroke, peripheral arterial occlusive disease or bypass surgery. Subgroup analyses of the physician survey by specialization are presented for questions on LDL-C relevance and treatment decisions. Descriptive statistics are shown for the survey data. Categorical variables were summarized using frequency counts and percentages. Continuous variables were summarized as means including standard deviation and medians. No formal statistical testing for group comparisons were performed. For the conjoint analysis, estimates were derived by a proportional hazard model based on a multinomial logit model with the physician's decision as dependent variable and the CVD risk attributes as independent variables. Continuous risk attributes were categorized. The relative importance of CVD risk attributes were calculated. The conjoint analysis was performed with SAS ${ }^{\circ}$, Version 9.3 (SAS Institute Inc., Cary, NC, USA).

\section{Declarations}

\section{Acknowledgments}

Medical writing support was provided by Dr. Karin Eichele (mediwiz). Clariness $\mathrm{GmbH}$ provided services for programming, hosting, recruitment and analysis of the survey. The survey and medical writing support were funded by Novartis Pharma $\mathrm{GmbH}$.

\section{Author contributions}

LB and KS designed and implemented the survey. OW contributed to the development of the survey. KS, LB and OW contributed to the analysis and interpretation of the results and to the writing of the manuscript. MW aided in interpreting the results and commented on the manuscript.

\section{Conflicts of Interest}

OW received lecture fees and honoraria for adboards from Sanofi-Aventis, AMGEN, Berlin-Chemie, Amarin Therapeutics, Novartis, Akcea Therapeutics and Hexal GmbH.

MW has received honoraria from Daiichi-Sankyo Deutschland GmbH.

LB and KS are employees of Novartis Pharma GmbH.

\section{Ethics declarations}

The survey has been conducted in accordance with all relevant guidelines and regulations applicable in Germany. This study is exempt from the need for ethical approval under local law ( $§ 15$ of the Professional Code of Doctors in Bavaria) as per advise received from the ethics committee of the Bavarian State Chamber of Health (EC reference number: 2021-1245). All patients participated voluntarily and informed consent to data collection, processing and analysis was obtained electronically from all subjects prior to the survey. Patient data were anonymized and aggregated for analysis. All physicians gave voluntary consent before participation. 


\section{References}

1. Wilkins, E. et al. European Cardiovascular Disease Statistics 2017. (2017).

https://ehnheart.org/component/attachments/attachments.html?task=attachment\&id=3115.

2. Statistisches Bundesamt (Destatis). Ergebnis 23211-0002. Gestorbene: Deutschland, Jahre, Todesursachen, Geschlecht. Stand: 13.04.2021. (2020). https://www-genesis.destatis.de/genesis/online?

operation=previous\&levelindex=1\&step=1\&titel=Ergebnis\&levelid=1618347547962\&acceptscookies=false\#abreadcrumb.

3. Townsend, N. et al. Cardiovascular disease in Europe: epidemiological update 2016. Eur Heart J 37, 3232-3245, doi:10.1093/eurheartj/ehw334 (2016).

4. Mach, F. et al. 2019 ESC/EAS Guidelines for the management of dyslipidaemias: lipid modification to reduce cardiovascular risk. Eur Heart J 41, 111-188, doi:10.1093/eurheartj/ehz455 (2020).

5. Ference, B. A. et al. Low-density lipoproteins cause atherosclerotic cardiovascular disease. 1. Evidence from genetic, epidemiologic, and clinical studies. A consensus statement from the European Atherosclerosis Society Consensus Panel. Eur Heart J 38, 2459-2472, doi:10.1093/eurheartj/ehx144 (2017).

6. Ference, B. A., Graham, I., Tokgozoglu, L. \& Catapano, A. L. Impact of Lipids on Cardiovascular Health: JACC Health Promotion Series. J Am Coll Cardiol 72, 1141-1156, doi:10.1016/j.jacc.2018.06.046 (2018).

7. Cholesterol Treatment Trialists, C. et al. The effects of lowering LDL cholesterol with statin therapy in people at low risk of vascular disease: meta-analysis of individual data from 27 randomised trials. Lancet 380, 581-590, doi:10.1016/S0140-6736(12)60367-5 (2012).

8. Vallejo-Vaz, A. J. et al. Low-Density Lipoprotein Cholesterol Lowering for the Primary Prevention of Cardiovascular Disease Among Men With Primary Elevations of Low-Density Lipoprotein Cholesterol Levels of $190 \mathrm{mg} / \mathrm{dL}$ or Above: Analyses From the WOSCOPS (West of Scotland Coronary Prevention Study) 5-Year Randomized Trial and 20-Year Observational Follow-Up. Circulation 136, 1878-1891, doi:10.1161/CIRCULATIONAHA.117.027966 (2017).

9. Cannon, C. P. et al. Simulation of Lipid-Lowering Therapy Intensification in a Population With Atherosclerotic Cardiovascular Disease. JAMA Cardio/ 2, 959-966, doi:10.1001/jamacardio.2017.2289 (2017).

10. Allahyari, A. et al. Application of the 2019 ESC/EAS dyslipidaemia guidelines to nationwide data of patients with a recent myocardial infarction: a simulation study. Eur Heart J 41, 3900-3909, doi:10.1093/eurheartj/ehaa034 (2020).

11. Ray, K. K. et al. EU-Wide Cross-Sectional Observational Study of Lipid-Modifying Therapy Use in Secondary and Primary Care: the DA VINCI study. Eur J Prev Cardiol, doi:10.1093/eurjpc/zwaa047 (2020).

12. Navar, A. M. et al. Lipid management in contemporary community practice: Results from the Provider Assessment of Lipid Management (PALM) Registry. Am Heart J 193, 84-92, doi:10.1016/j.ahj.2017.08.005 (2017).

13. Egidi, G. et al. Neue DEGAM-S3 Leitlinie „Hausärztliche Beratung zur kardiovaskulären Prävention“. Z Allg Med 93, $312-$ 318, doi:10.3238/zfa.2017.0312-0318 (2017).

14. Barter, P. J. et al. Gaps in beliefs and practice in dyslipidaemia management in Japan, Germany, Colombia and the Philippines: insights from a web-based physician survey. Lipids Health Dis 19, 131, doi:10.1186/s12944-020-01265-z (2020).

15. Gemeinsamer Bundesausschuss. Richtlinie des Gemeinsamen Bundesausschusses über die Gesundheitsuntersuchungen zur Früherkennung von Krankheiten (Gesundheitsuntersuchungs-Richtlinie). (2021). https://www.g-ba.de/downloads/62-492-2383/GU-RL_2020-11-20_iK-2021-02-12.pdf.

16. Kordonouri, O. et al. New approach for detection of LDL-hypercholesterolemia in the pediatric population: The Fr1dolinTrial in Lower Saxony, Germany. Atherosclerosis 280, 85-91, doi:10.1016/j.atherosclerosis.2018.11.011 (2019).

17. Kelly, R. B. Diet and exercise in the management of hyperlipidemia. Am Fam Physician 81, 1097-1102 (2010).

18. Stirratt, M. J. et al. Self-report measures of medication adherence behavior: recommendations on optimal use. Trans/ Behav Med 5, 470-482, doi:10.1007/s13142-015-0315-2 (2015). 
19. Brandts, J. \& Ray, K. K. Low Density Lipoprotein Cholesterol-Lowering Strategies and Population Health: Time to Move to a Cumulative Exposure Model. Circulation 141, 873-876, doi:10.1161/CIRCULATIONAHA.119.043406 (2020).

20. Dogan, V. et al. Evaluation of perceptions, knowledge and compliance with guidelines in real-life practice: A survey on the under-treatment of hypercholesterolemia. Turk Kardiyol Dern Ars 47, 599-608, doi:10.5543/tkda.2019.39293 (2019).

21. Nielsen, S. F. \& Nordestgaard, B. G. Negative statin-related news stories decrease statin persistence and increase myocardial infarction and cardiovascular mortality: a nationwide prospective cohort study. Eur Heart J 37, 908-916, doi:10.1093/eurheartj/ehv641 (2016).

22. Navar, A. M., Stone, N. J. \& Martin, S. S. What to say and how to say it: effective communication for cardiovascular disease prevention. Curr Opin Cardio/ 31, 537-544, doi:10.1097/HCO.0000000000000322 (2016).

23. Heigl, F. et al. Lipidological competence centres and networks: Future perspectives to improve healthcare of patients with disorders of lipid metabolism. Atheroscler Supp/30, 63-71, doi:10.1016/j.atherosclerosissup.2017.05.014 (2017).

24. Arafa, A. E., Anzengruber, F., Mostafa, A. M. \& Navarini, A. A. Perspectives of online surveys in dermatology. J Eur Acad Dermatol Venereo/ 33, 511-520, doi:10.1111/jdv.15283 (2019).

25. Taddicken, M. Methodeneffekte von Web-Befragungen: Soziale Erwünschtheit vs. Soziale Entkontextualisierung in Umfrageforschung: Herausforderungen und Grenzen (eds Martin Weichbold, Johann Bacher, \& Christof Wolf) 85-104 (VS Verlag für Sozialwissenschaften, 2009).

26. Hibbard, J. H., Mahoney, E. R., Stockard, J. \& Tusler, M. Development and testing of a short form of the patient activation measure. Health Serv Res 40, 1918-1930, doi:10.1111/j.1475-6773.2005.00438.x (2005).

27. Insignia Health. Patient Activation Measure ${ }^{\circledR}(P A M \Theta)$, https://www.insigniahealth.com/products/pam-survey (2019).

28. Assmann, G., Cullen, P. \& Schulte, H. Simple scoring scheme for calculating the risk of acute coronary events based on the 10-year follow-up of the prospective cardiovascular Munster (PROCAM) study. Circulation 105, 310-315, doi:10.1161/hc0302.102575 (2002).

\section{Figures}

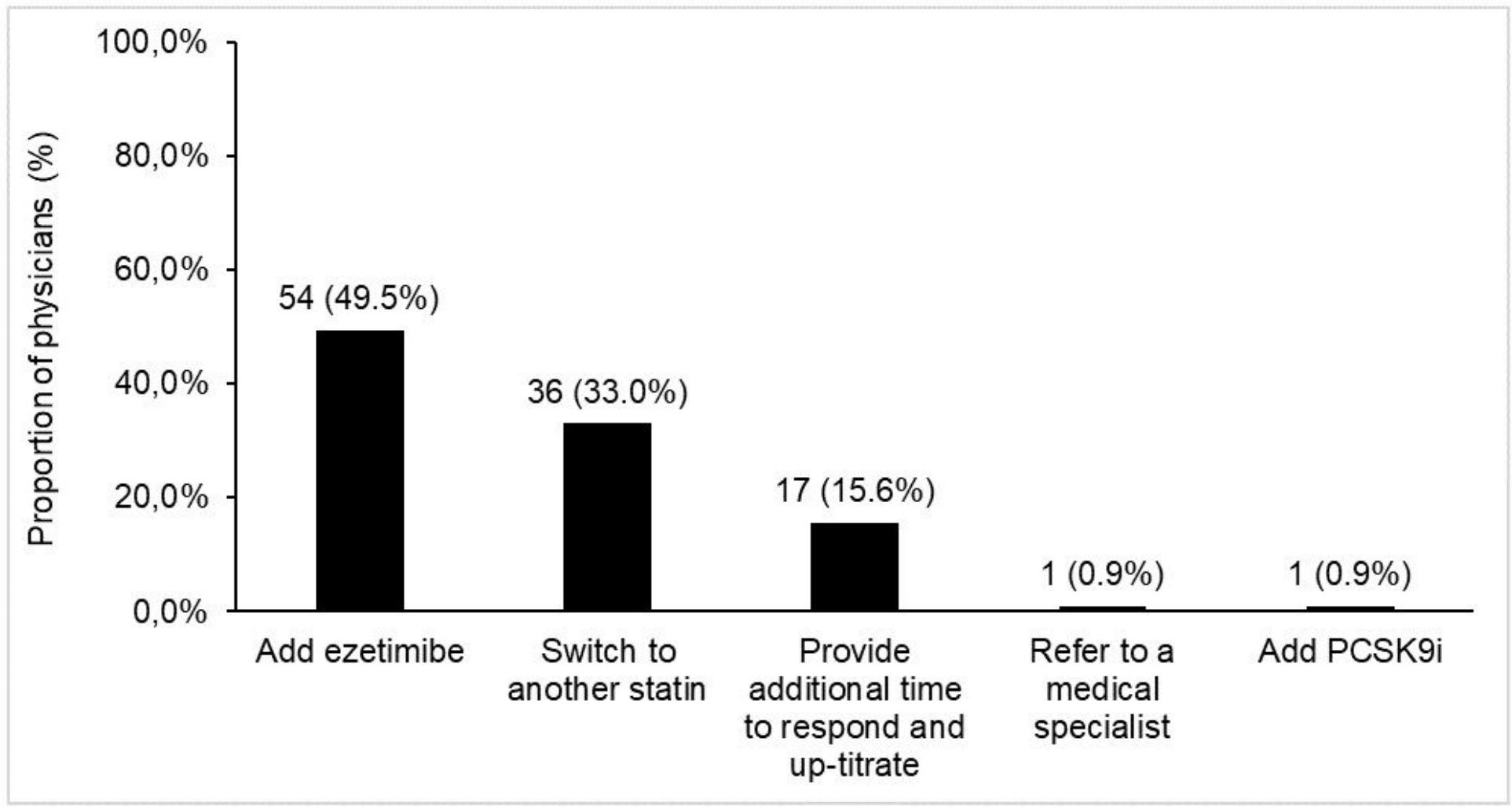


Figure 1

Preferred treatment optimization options

a

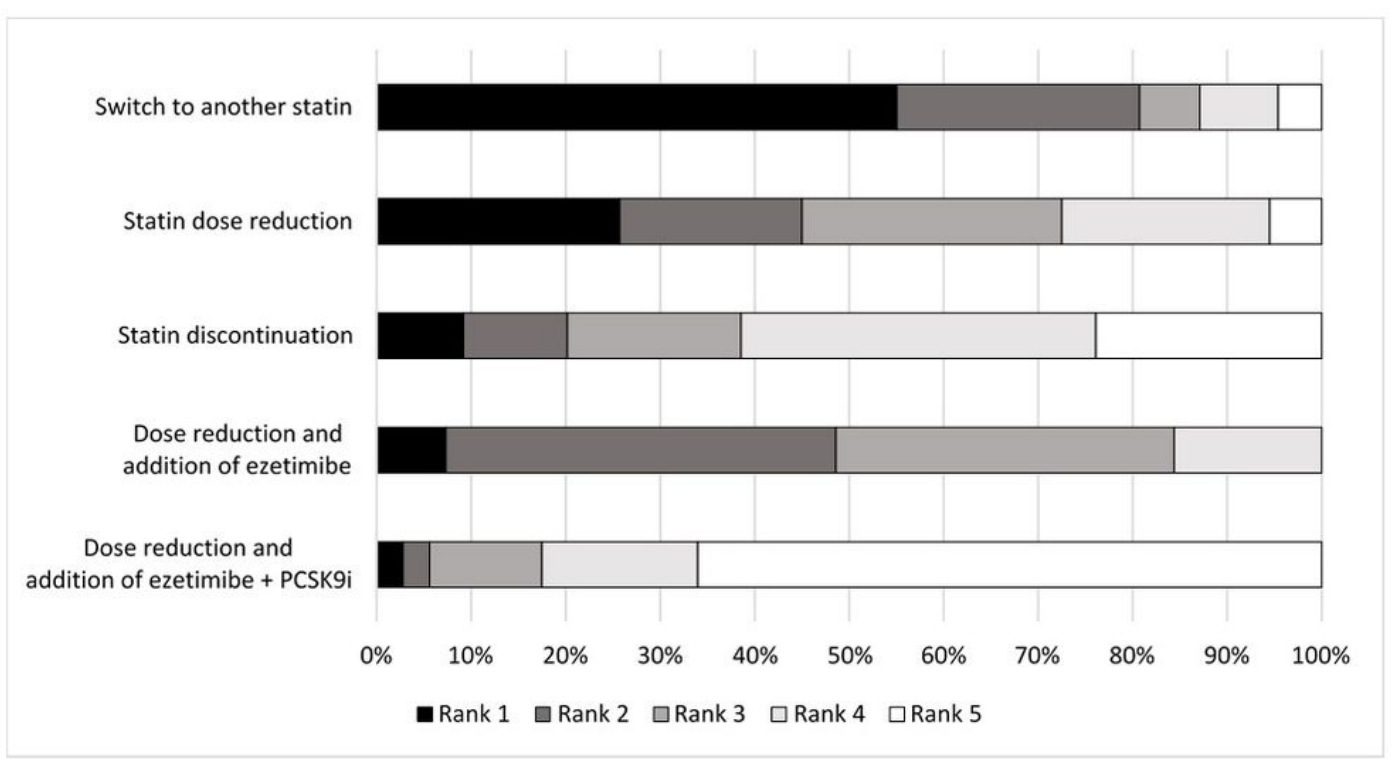

b

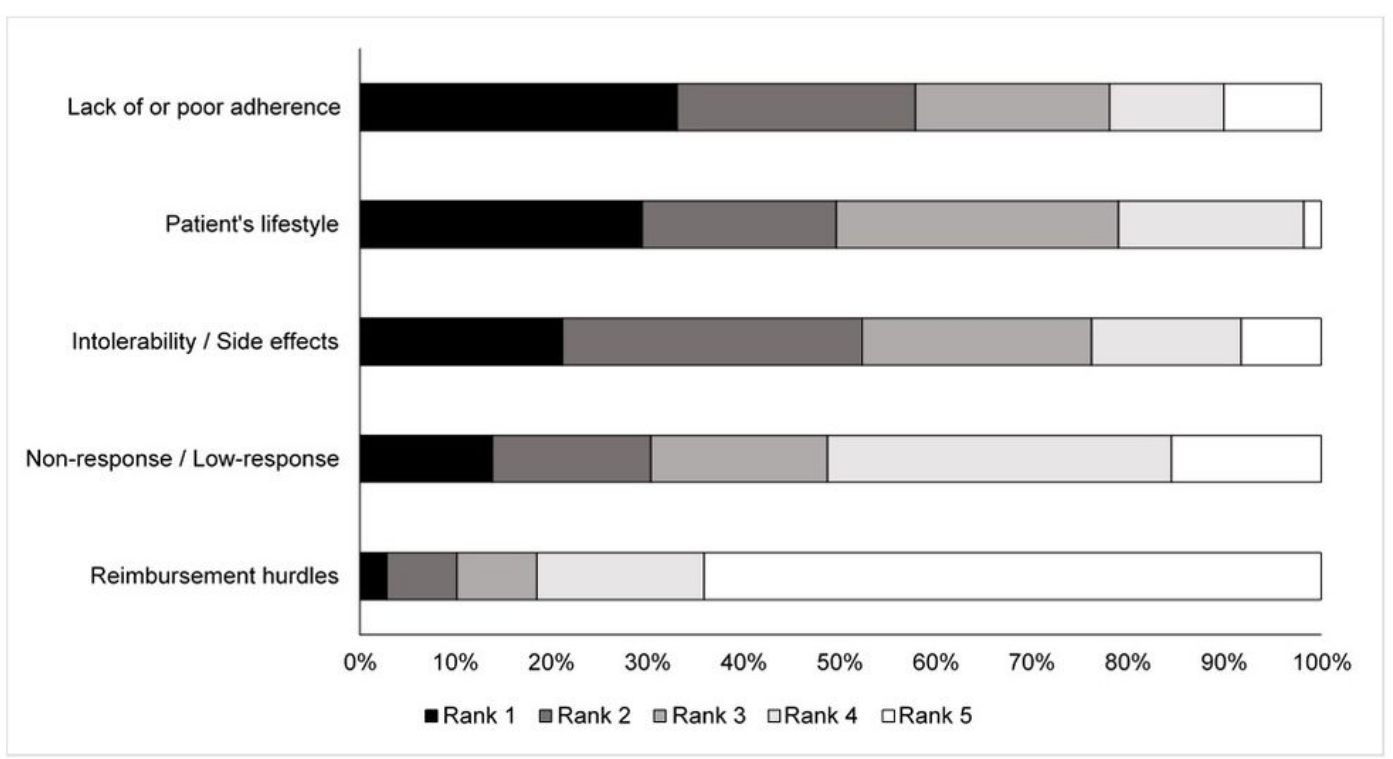

Figure 2

a) Treatment optimization in case of statin intolerance; b) Main reasons for target attainment failure according to physicians

\section{Supplementary Files}

This is a list of supplementary files associated with this preprint. Click to download.

- PROCYONManuscript1Final20211012Supplement.docx 